\title{
The Impact of Urban Requalification on Municipal Governance: an Analysis from Mozambique
}

\section{Jochua Abrão Baloi}

Faculty of Ethics, Human and Legal Sciences of the University of Saint Thomas of Mozambique, Maputo-Mozambique.

Email: jbaloi@yahoo.com.br

\begin{abstract}
:
The purpose of this article is to analyze the impact of urban requalification on municipal governance, taking as a starting point the Mozambican reality. The central argument is that the urban requalification had a positive impact on the municipal governance process and contributed to local development. Thus, the question that guides this article is what is the impact of urban requalification on municipal governance in Chamanculo " $D$ " neighborhood? Therefore, this article concludes that requalification is one of the means by which the municipality of Maputo has served in its governance process to inculcate local development.
\end{abstract}

Keywords :

Urban re-qualification; intervention; planning; resettlement.

\section{Introduction}

This article comes about with the objective of analyzing the impact of urban requalification on municipal governance in Mozambique, analyzing the case of Chamanculo " $\mathrm{D}$ " neighborhood in Maputo Municipality. According to Maputo City Municipal Council (2016), Chamanculo "D" neighborhood is located in Nhlamankulu Municipal District.

Chamanculo " $\mathrm{D}$ " neighborhood, because it was in a disorganized location, and the residents were living spontaneously, had no coverage in terms of primary solid waste collection services and therefore the incidence of poverty was $51 \%$ of the local population. As a result, the streets were rundown and potholed, the drainage system did not allow storm water to flow, and it was difficult to provide power and install a quality and quantity water supply network that would meet the needs of the local consumer. Most of the houses were of precarious material, i.e. conventional, being of wood and zinc or with reed walls.

In spite of the urban requalification of this neighborhood, it was necessary to guarantee the often-obsolete access roads, to remodel the drainage of rainwater, to rebuild the electricity network, and in general to remodel the urban situation of this neighborhood, whose project covered a total area of 140 hectares, consisting of 74 blocks with over 6,000 residents.

The central argument of this paper is that urban requalification had a positive impact on the municipal governance process and contributed to local development. The question that guides this article is what is the impact of urban requalification on municipal governance in Chamanculo " $D$ " neighborbood? The hypothesis that can be advanced in this article is that the urban requalification of Chamanculo "D" neighborhood improved the urban quality of life of its residents.

The project of urban requalification would consist in the creation of a drainage system that would allow the drainage of rainwater, since under current conditions it was difficult to supply energy and install a quality water supply network in the neighborhood, a scenario that expected to change with the requalification. In the urban remodeling, the plan defined the type of constructions 
that would be made, which was expected to result in the replacement of timber and zinc houses with buildings of vertical construction.

The methodological construction that guides this article involves a symbiosis of several methods (Qualitative, Monographic, Historical, Bibliographic), combining them with the hermeneutic-reflective for the effective reach of the theoretical and historical reference of the impact of urban requalification on municipal governance. This paper is divided into three parts, besides the introduction and conclusion. In the first, the theoretical framework on the problematic in question is presented; then, the partial plan of the urbanization of Chamanculo " $\mathrm{D}$ " neighborhood is discussed in detail and finally, the main research results are presented.

\section{Review of Literatures}

\subsection{Conceptualization}

According to Enriquez (1998), local development is defined as a complex process of agreement between agents that interact within the boundaries of a given territory in order to drive a common project. This project combines the generation of economic growth, equity, change, social and cultural, ecological sustainability, gender focus, quality, spatial and territorial balance, in order to raise the quality of life and well-being of each family and citizens living in that territory.

For Juarez (2008), local development is conceived as the process of becoming dynamic, the comparative and competitive advantages of a given locality, to favor economic growth and simultaneously raise human, social and corporate capital, as well as achieving sustainable use of natural capital, because, the people who make the local development lives in the locality. There is no local development without the interest, involvement, commitment and adhesion of the local community.

According to Martins (2001), local development is an event resulting from human thought and action, which confronts the challenge of facing basic problems and reaching elementary and self-referenced levels of quality of life in the community.

According to Buarque (1999), local development implies articulation between the different actors and spheres of power, civil society, non-governmental organizations, private and political institutions as well as the government itself. Thus, each actor has a role to play in achieving local development. For this author, it is an endogenous process registered in small territorial units and human groups capable of promoting economic dynamism and improving the quality population life.

In Borba's (2000) perspective, local development implies that localities and territories have economic, human, institutional, environmental and cultural resources, as well as untapped economies of scale, which constitute their development potential, which can improve the local population welfare.

The definitions referenced above are somewhat complex, although they are complementary in their comprehension. Nevertheless, for the purposes of this article, it is considered the Martins (2001) definitions, which state that local development is an event resulting from human thought, and action, which faces the challenge of different problems since it is in the community that the elements that contribute to the development of society are verified.

According to Silva (2011), urban requalification is a social and political process of intervention in the territory that essentially aims to (re) create the urban quality of life through 
greater equity in (urban) forms of production, a marked balance in the use and occupation of spaces and in the creative and innovative capacity of the agents involved in these processes.

Domingues (2006), quoted by Silva (2011), argues that urban requalification is now seen as one of the purposes of urban intervention policies and, in this sense, a set of rules and determinations must be imposed, to defend and to ensure the protection and enhancement of the characteristics of a territory, such as physical aspects, the environment and historical-cultural identity.

For Carvalho (2008), quoted by Silva (2011), urban requalification aims to improve the quality of environment and life in cities, and involves the articulation and integration of various components, such as housing, culture, social cohesion and mobility. Indeed, strategies for urban upgrading, in line with key contemporary trends and guidelines in urban development and planning, reveal the primacy of reusing existing infrastructure and equipment over the new construction and reusing / reconverting urban spaces areas (vacant, abandoned or degraded in particular) with the aim of improving their conditions of use and enjoyment.

Therefore, as can be inferred from these authors, the requalification of the Chamanculo "D" neighborhood meets the literature, in order to achieve the main objective advocated, which is to improve the quality of life of the residents of that neighborhood.

In this perspective, urban requalification must be characterized not only by functional, but also political, social and environmental criteria. These criteria give interventions a new not only economic but also social vitality (Vaz \& Silveira, 1999). This is what is intended with the requalification of Chamanculo "D" neighborhood.

Urbanization as a process and the city as a concrete organism are processes that truly mark contemporary society. Because now spaces is understood as a historical construction and cities are the result of a whole process that accumulates transformations that happen over time, tied by all the relationships established in each different historical moment, due to specific needs (Vaz \& Silveira, 1999).

As can be inferred from these authors, urban requalification must be inserted in the strategic planning of the city, as well as in the master plan, as has been happening in Maputo city. Therefore, urban requalification is increasingly required for the well-being of city dwellers. For these elements, it was thought about the urban requalification of Chamanculo " $\mathrm{D}$ " neighborhood.

\subsection{Local Development Theory}

According to Barquero (2001), local development emerges as a community's response to the social precariousness produced by the introduction of technological changes motivated by the need for production efficiency in the 1980s.

According to Niederle \& Radomsky (2016), the emergence of the notion of local development is the result of two important transformations. The first concerns to the emergence and multiplication of civil society organizations and non-governmental organizations, which were dedicated to implementing actions in local spaces. The second refers to the broader process of decision decentralization, in which the State assigns responsibility to local actors to promote and recreate forms of public resource management. 
For Benko \& Pecqueur (2001) through local development, there are cities around the world that have emerged as political and economic actors, increasingly acquiring a strong role and definitively assuming centrality in the creation and dynamization of symbolic goods and welfare of its population. Territorial planning policies, under the responsibility of the central power until the 1980s, were delegated to local territorial authorities.

According to Bastos (2005), during the 1970s and 1980s, a major economic, social and political restructuring took place in Mozambique. At the time, the idea of local development was not a priority, because development was thought in national terms, being driven by central governments. From 1980 onwards, the idea of local development become a priority, and the central government shifted the task of local development policies to lower levels (municipalities).

Koehnen \& Cristóvão (2006) argue that the process of local development implies a common vision, articulating initiatives of economic, social, cultural, political and environmental dimensions, because for them, local development is primarily a common will to improve the daily life. This will is based on confidence in one's own resources and in the ability to combine them rationally to build a better future. Local development involves the dimensions of autonomy, citizenship and participation of local actors to combat local inequalities and seek innovative solutions.

\section{Discussion}

\subsection{Partial Plan of the Urbanization of Chamanculo " $D$ " Neighborhood 3.1.1. Plan Intervention Area}

The Maputo municipality has an area of 34,677 hectares or $346.8 \mathrm{~km} 2$ and, according to INE (2017), and a population of 1.110 .170 inhabitants, representing an increase of $13.2 \%$ over the previous census conducted in 2007.

Chamanculo district is located in Maputo City. It is one of the largest informal neighborhoods in the city, where several roads can make the access to its interior, such as: Labor Avenue, Robby's Brothers Street, Joaquim Chissano avenue and Mozambique Avenue. This neighborhood was built in 1919 with the purpose of integrating socially and urbanistically the natives from the countryside. There is very little documentation about the creation of the neighborhood and therefore it is difficult to know the rules followed for its occupation.

The consultation of the Municipal Plan, prepared under the Maputo Municipal Urban Plan (PEUMM, 2009), shows that, from an administrative point of view, Maputo is divided into 7 Municipal Districts, which in turn they are divided into administrative units called "neighborhoods".

Chamanculo "D" neighborhood together with Airport A and B neighborhoods, Xipamanine, Minkadjuine, Unit 7, Chamanculo A, B and C, Malanga and Munhuana belong to the ka Nlhamankulu Municipal District covering a total area of about 880 hectares, where approximately 129.306 inhabitants live (NIE, 2017).

According to the Maputo Municipal Urban Structure Plan (2009), this district is characterized by having primary activities directed to subsistence agriculture (self-consumption and local exchange), indicating the existence of markets that have more transactions and more traders own, namely Xipamanine and Malanga. It is also noteworthy the existence of health equipment at the level of Hospital and Health Centers. 
The Maputo Municipality Urban Structure Plan (2009) states that Maputo, the capital of Mozambique, is the most populous urban region in the country, where about $54 \%$ of the population lives below the poverty line and 75\% (800.000 people) live in informal settlements with very poor housing and sanitary conditions. About $42 \%$ of residents without access to piped water, $58 \%$ without access to the sanitation system, $85 \%$ live in areas where there is no rain drainage system ${ }^{1}$.

Our study will be based on Chamanculo "D" neighborhood, located in Maputo City Municipality and which together with A, B, C neighborhoods, constitute the old Chamanculo neighborhood, considered the suburb of Maputo City.

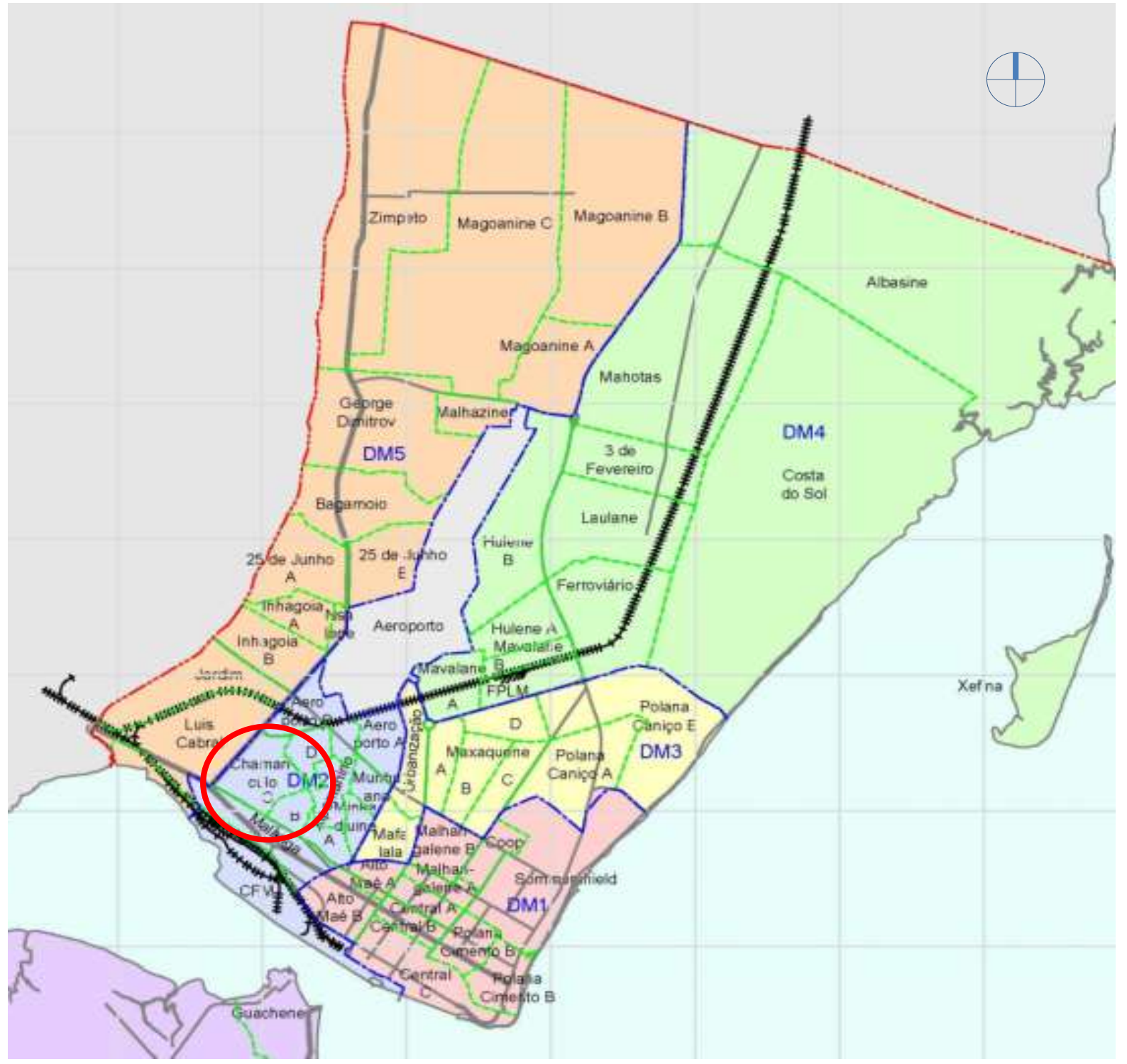

Figure 1. Framework of the intervention area in the Municipality - City Source: Maputo Municipality Plant (PEUMM, 2009)

${ }^{1}$ Characterization of Maputo City Informal Settlements” - Report II, Arch. Luís Lage, 2013. 
Chamanculo " $\mathrm{D}$ " neighborhood is an informal settlement located to the northwest of Maputo city center (known as "cement city", ka Mpfumo Municipal District) and is bounded to the west and north by Chamanculo $\mathrm{C}$ neighborhood, Mozambique Avenue and Unit 7; to the East by the Airport B neighborhood, Xipamanine neighborhood; to the South by the Chamanculo B neighborhood. In this area, with about 140 hectares, according to the 2017 Census, there are approximately 25.318 inhabitants (NIE, 2017).

\subsubsection{Restructuring Scope and Steps}

The Maputo City Municipal Council, within its overall strategy for the reorganization and urbanization of informal settlements, as part of the Maputo Municipal Development Program (PROMAPUTO II), and in fulfillment of one of its strategic objectives, which provides for the provision of instruments management is implementing a pilot project for urban upgrading, called Chamanculo "D” Neighborhood Rehabilitation Support.

This project, approved in 2009, is part of the Brazil-Mozambique-Italy-Cities Alliance Technical Cooperation, with the participation of the World Bank. All of these countries wanted to improve the quality of life of the informal settlement population called Chamanculo " $D$ ", which is foreseeing the execution of a set of studies and projects necessary for the integrated requalification and regularization of the area. As well as the actions to promote the socioeconomic development of the population residing in the area and the execution of priority works.

As part of this project, the Maputo City Municipal Council, in partnership with the Italian Development Cooperation, carried out the elaboration and implementation of the Partial Urbanization Plan of Chamanculo "D" neighborhood.

The Plan of Urban Structure of the Municipality of Maputo approved in 2009, indicates as one of the priorities the insertion of informal settlements in the formal city, establishing that neighborhoods included in spaces whose urbanization is incomplete, that is, characterized by the lack of complete urban infrastructures should be restructured.

This priority is foreseen in the Maputo City Municipal Council Five-Year Program (20092014), while also will be maintained in the new 2015-2020 program and in the actions of the Maputo Municipal Development Program - PROMAPUTO, designed to a ten-year period (20072017). Partially was funded by the World Bank, with the aim to enhancing the capacity of the City Council to develop, manage and maintain quality service delivery to the city's inhabitants 


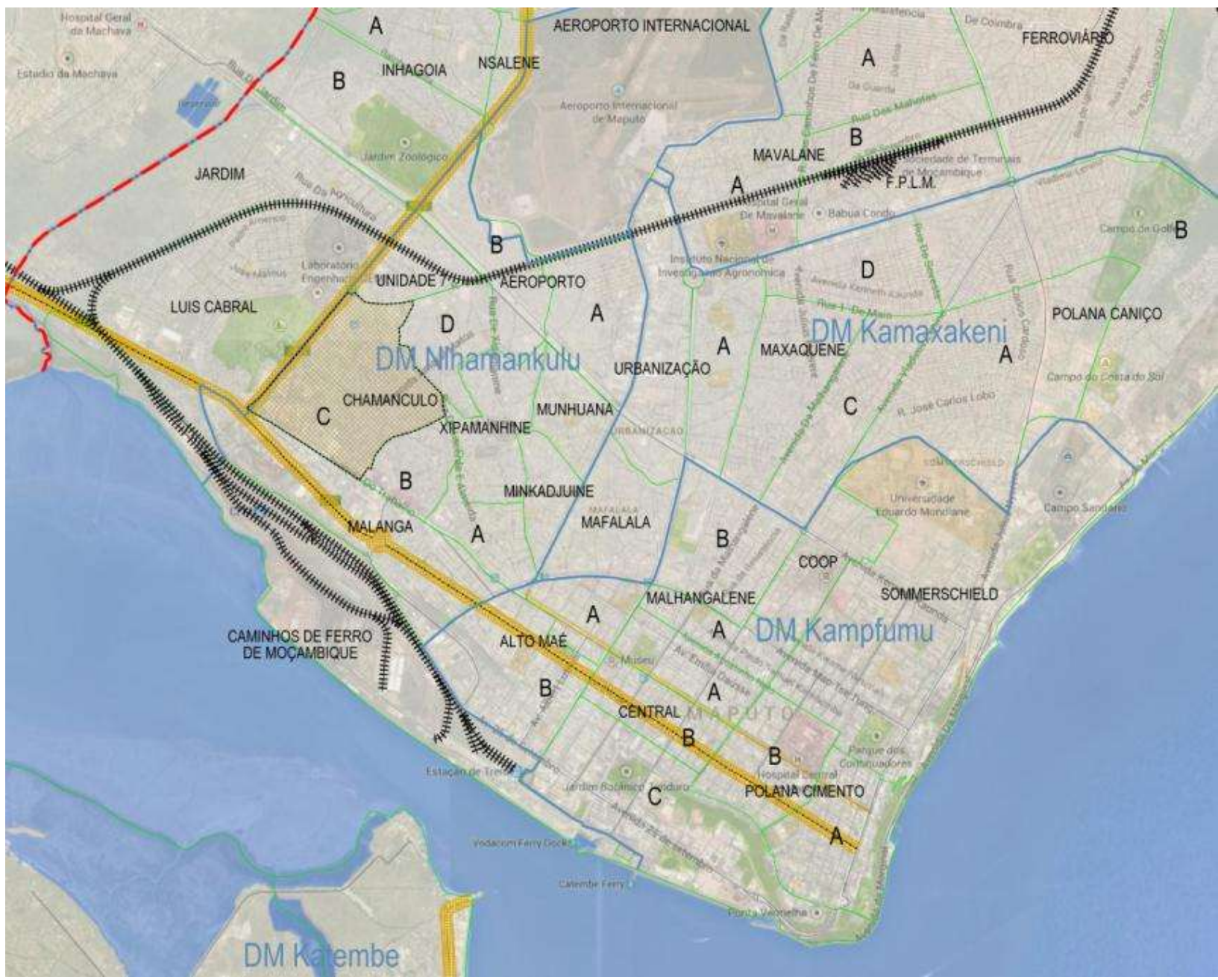

Figure 2. Map-Plan of Chamanculo "D" Neighborhood

Source: Google Maps

According to what is planned in the works, for the materialization of this plan, it is necessary to make a report of the initiation of the work. The other thing needed is to set up a monitoring committee, to hold the first public hearing, to prepare the preliminary proposal of the Partial Plan of Urbanization, which constitutes this research, to hold the second public hearing and finally to draft a final proposal of the plan (Maputo City Municipal Council, 2008).

In April 2015, the Work Initiation Report was prepared and the monitoring committee of the Partial Urbanization Plan was established. On 12 May 2015, the first public hearing was held on the presentation of the results for the diagnosis of the current situation ${ }^{2}$ and the first development scenarios of the Chamanculo " $\mathrm{D}$ " neighborhood.

\subsubsection{Residential Spaces to be Restructured}

The residential spaces to be restructured correspond to the unplanned residential areas which urban reorganization is proposed in terms of land regularization (reparcelling) and infrastructure. These new residential areas should ensure resettlement of the population from resettlement areas, promoting the creation of qualified housing.

\footnotetext{
${ }^{2}$ Integrated Diagnosis of Chamanculo "D” neighborhood, prepared in 2014 by the Central Indian-Plural Consortium-SIPCA.
} 
In these spaces should predominate the housing functions and may also accommodate other compatible uses such as commerce, services, tourism, social facilities, green areas, warehouses, small industrial establishments and others as long as compatible with housing use and comply with the legislation in force with regard to environmental issues. In particular, as regards noise or other polluting or unhealthy effects, and have no inconvenience in terms of parking and movement.

The Maputo Municipality Urban Structure Plan (2009) states that, in these cases, $60 \%$ of predominantly housing areas should be targeted at lower-income citizens, giving priority to public and private initiatives of social housing developments. On the other hand, $3 / 4$ of the area to be intervened must provide for multifamily housing (average population density, exempting elevator use.

These spaces are divided into 2 types: Residential spaces to be restructured Type I, which correspond to areas of higher density, where it is expected to occupy a maximum of four floors, in collective housing types (band, semi-detached or isolated). These are located between the places occupied by equipment spaces to the southwest and proposed new residential areas (space between Amaral Matos Avenue and Chamanculo road). Between the place destined to spaces of economic activities to the south, areas intended for residential spaces to be restored of type II, in the surroundings of Carlos Morgado Street (to the northeast). To the north near the Unity 7 school, the multifunctional spaces and near the Recheio shopping center.

Residential spaces to be restructured type II, where these areas are intended for a medium-density urban occupation, with a maximum of two floors and typologies of two-family or single-family housing (townhouse, semi-detached or isolated). These areas complement the residential spaces to be maintained and are associated with eight areas: the neighborhood delimited by Marcelino dos Santos Street and Silex Street, the neighborhood adjacent to Estofaria Matlhonhana, bounded by Xipamanine Street.

\subsubsection{Proposed Residential Spaces}

The proposed Residential Spaces correspond to new planned residential areas, for which it is proposed the creation of residential areas, land regularization (reparcelling) and infrastructure. These new residential areas should ensure resettlement of the population from resettlement areas by promoting the creation of qualified housing.

In these spaces should predominate the housing functions and may accommodate other compatible uses such as commerce, services, tourism, social facilities, green areas, warehouses, small industrial establishments and others. These areas must be compatible with housing and comply with current legislation regarding to environmental issues, such as noise or other polluting or unhealthy effects, and do not present any inconvenience in terms of parking and circulation (Maputo City Municipal Council, 2009).

These spaces are divided into 2 types: Proposed Type I residential spaces, which correspond to an area covered by airport servitude, near the northeastern limit of the intervention area, delimited by Carlos Morgado Street (to the north), Amaral Matos Avenue (to the south), Chamanculo street to the west, Mbongoluene street (to the east). In these places, the upper floor limit is set at three. It foresees an occupation in collective housing typologies (band, semi-detached or isolated). 
Proposed residential spaces of type II, which foresee an occupancy with a maximum of four floors, in collective housing typologies (townhouse, detached or isolated). These proposed type II areas are located in the south of Amaral Matos Avenue and in the east of Mbongoluene Street.

\subsubsection{Execution Plan}

In accordance with Yusnadi, Lubis, Nuraflah (2019, p. 288), policy is the initial planning of the development strategy. Starting a program with policy can provide a basic framework before planning and strategy are implemented, on the contrary a plan will operationalize the policies that have been set up to achieve a goal.

In the specific case of the Chamanculo " $\mathrm{D}$ " neighborhood, as well as others where informal housing has a significant presence, it was concluded that it would be difficult to devise very different strategies and scenarios, due to the narrowly realistic scope for intervention. Thus, in line with the Maputo City Municipal Council, it was decided to replace the alternative scenarios with time steps, constituting successive phases until the full realization of the proposed Plan (Maputo City Municipal Council, 2008).

In the Initial Phase (Phase I), a set of priority interventions was framed for which there are strong short-term possibilities to be initiated. This stage establishes as priority interventions for the neighborhood, the intervention in the Amaral Matos Avenue, the interventions in the Carlos Morgado Street and the intervention in the Xipamanine Street that crosses the airport district across.

The Intermediate Stage (Phase II) provides for most of the interventions southwest of the neighborhood, an area that develops along Amaral Matos Avenue. The other places are the space for economic activities along Mbongoluene Street and northeast of the neighborhood along Chamanculo Street (the east and west of this road) in south space of the Buses Terminal and in the space delimited by Silex Street (Maputo City Municipal Council, 2009).

The interventions foreseen at this stage cover a wide variety of urban space typologies, namely multifunctional spaces, residential spaces (proposed type I and type II and restructuring type I and type II), economic activity spaces (proposed) and a new equipment space (proposed).

The Final Phase (Phase III) provides for intervention in the unplanned areas of higher density existing in the neighborhood, mainly affecting urban spaces to be restructured type I, for which it is proposed their land regulation/reparcelling and infrastructure. Intervention is also planned in an unplanned neighborhood, near the southeastern limit of the intervention area, affecting urban spaces to be restructured type II. It is also foreseen the creation of two multifunctional urban fronts, one next to Marcelino dos Santos Street, and another next to Xipamanine Street, thus seeking to boost the functional diversification of the neighborhood. These new residential areas should ensure the housing needs arising from resettlement processes (Maputo City Municipal Council, 2009).

\subsection{Analysis and Discussion of Research Data}

\subsubsection{Chamanculo " $D$ " neighborhood requalification process}

The preparation of the requalification of the Chamanculo " $\mathrm{D}$ " neighborhood, a Methodological Manual of intervention integrated in informal settlements for the city of Maputo was prepared, whose intervention cycle is structured in a sequence of interdependent phases that are outlined below. 
According to the Maputo City Municipal Council (2016) the implementation of the paving projects of some avenues and the reconstruction of the existing drainage ditch in Chamanculo "D" Neighborhood as part of the Project "Support for the Rehabilitation of the Chamanculo "D" and PROMAPUTO, affected the housing of the residents.

In addition to involving the resettlement of electrical, telephone and water infrastructures, belonging to the companies Electricity of Mozambique (EDM), Telecommunications of Mozambique (TDM) and Water Supply Investment and Equity Fund (FIPAG) respectively affected as well the housing through the displacement of fences and remodeling of residences and tents.

Fifty-Seven families was displaced to Chiango, Albazine neighborhood, seventeen of them was associated with the following: Drainage Rehabilitation Works: three (three) families subjected to resettlement with a final cost of 799.980,71 Meticais ${ }^{3}$, Paving Project of Av. Amaral Matos: 14 (fourteen) families with total affectation at the cost of 4.560.467, 07 Meticais.

About $14.9 \%$ of the population are household heads. Just over half $(50.6 \%)$ of the affected population is female. Most (91.4\%) of household members are permanent residents of the household, while a smaller percentage $(2.2 \%)$ are working elsewhere in the country (Maputo City Municipal Council, 2016).

The average age of household members is 34 , which means that the affected population is mostly young. Almost half (44.3\%) of household members have completed primary level (1st to 7 th grade), while $28.6 \%$ have no education and $26.7 \%$ have completed secondary level (8th to 10 th grade), and there are also a very small percentage $(0.4 \%)$ of members who can only read and write their name and some numbers.

However, 50.1\% of children aged 6 to 15 are enrolled, of which $44.1 \%$ are enrolled in primary education and only $5.8 \%$ in secondary education. About $76 \%$ of the children were enrolled in schools within 5-30 minutes of their place of residence. This is due to the fact that primary schools are located in close proximity to homes, with 17\% being in schools less than 5 minutes from home. Only 7\% of children went to schools more than 30 minutes away. To get to school, $77 \%$ of children traveled on foot. About 16\% used private cars and 7\% used public transport (Maputo City Municipal Council, 2016).

The average number of years interviewed households lived in the homes is 30 to 40 years. The main house was acquired by self-construction (73.4\%), and $17.1 \%$ received the inheritance housing and $9.5 \%$ made the purchase. Regarding the walls, $51.7 \%$ were completely painted and $48.3 \%$ partially painted. For some (2.4\%), the main houses had an approximate value of $250.000,00$ Meticais and an equal percentage evaluated the houses as having an approximate value of 150.000,00 Meticais, the others did not answer or do not know what is the value of their house.

\subsubsection{Resettlement Action Plan}

In order to carry out resettlement, a Resettlement Action Plan (RAP) was prepared from July 2014 to February 2015, with families moving to the Albazine neighborhood in March 2015. The plan was intended to ensure that the affected community had an improvement in living conditions, guaranteed involvement in the process, the establishment of fair compensation for lost or affected assets, and the establishment of grievance and dispute settlement mechanisms.

\footnotetext{
${ }^{3}$ One (1) Metical is currently approximately 65USD.
} 
Under the plan, three (3) public consultations were held. The first intended primarily to inform the public and those affected, of the intention of the Maputo City Municipal Council to carry out works in the neighborhood. The second was to inform to the affected and interested parties, on the general list of those affected, and the last was to identify the affected infrastructure in detail (Maputo City Municipal Council, 2016).

Noteworthy is the fact that the Project only provided: financial resources for the payment of compensation to those affected, Plot Assignment and Right of Use and Harnessing of Land (DUAT) by the Municipal Council and affection to the process of a social and urban team, with their logistical support.

Thus, the conditions affecting resettlement were thus formulated based on these assumptions and the need for reinforcement of financial resources by the Municipal Council regarding compensation and logistical support to families.

In the implementation of the Resettlement Action Plan, the following activities were highlighted: Plot assignment and Right of Use and Harnessing of Land (DUAT's) and payment of the affected improvements, so the affected could remove and take advantage of existing elements and materials in the houses to be demolished. Transportation of goods to the place of reception, by means of transport of the Municipality and with the accompaniment of the technicians of the social and urban team. The Self-construction followed-up at the shelter, where simplified basic designs of Type 2 and Type 3 housing were provided as required by each affected household. The municipality has made some institutional negotiation with Electricity of Mozambique (EDM) and Waters of Maputo Region (AdeM) to establish home connections (Maputo City Municipal Council, 2016).

During the implementation of the Resettlement Action Plan, despite the reinforcement of communication with local entities and regarding the plots available to families, some conflicts situations happened with the alleged "natives" of the Albazine neighborhood who claimed to be holders of the land. This situation has been remedied given the existence of Right of Use and Harnessing of Land (DUATs) by resettling families.

According to Ismali (2019, p.72), the rights set forth in the agrarian law relating to land, the government should realize that by setting these rights to utilize land which they are entitled to good and to perform its obligations towards the ground, and this has happened on land granted by the municipal government.

At the insertion level in the host community, the Project Management Unit (PMU) made the necessary contacts to facilitate the resettlement insertion in the local community, namely the contact with the local structures of the neighborhood, the block chiefs and the secretary of neighborhood. This process was also accompanied by the Chamanculo "D" neighborhood secretary and began by indicating the plots to be allocated to those affected and listening to the opinions of families regarding to the identified location (Maputo City Municipal Council, 2016).

\subsubsection{Current State of Buildings (Resettled Dwellings)}

The process of housing construction in relation to the allocated amounts was largely influenced by the willingness of families to have larger houses in terms of typology. The choice has resulted in the situation where most of the houses are unfinished, because the funds received 
were insufficient for the type of house that was built, even though these houses have minimum conditions for residence.

Awareness raising actions were carried out, together with the local structures of the neighborhood (secretary, block chiefs), to inform the population about the critical issues that pose risks to residents, especially children, with emphasis on:

\section{- The sewage (the pits)}

Due to the lack of a municipal wastewater system in place, households often resort to the wastewater treatment system located in the field by means of a sump and drain (Maputo City Municipal Council, 2016). The constructive system of self-construction and evolution coupled with the expectations of families, always exceeding the financial availability, and did not allow the realization of all works in a timely manner that could be used when finished. So the sewage treatment system via septic tanks in some cases, as the work progresses, it has been replaced by improved latrines. Currently it is found that all families use septic tanks for sanitation.

\section{- The compartments and other unfinished elements}

The evolutionary self-construction model, together with the fact that families preferred to make larger houses than those they had in the neighborhood of provenance, led to the existence of some unfinished buildings, as well as houses with unfinished compartments, as well as doors and windows for fixing, some walls for plastering and painting. However, most families are residing in these houses, as the compartments in use have essential characteristics for housing (Maputo City Municipal Council, 2016).

\section{- Open water wells for construction and others}

Due to the lack of potable water near the site, families resorted to the beginning of the resettlement process to wells to obtain water to build their homes. Many of these wells are currently closed due to the fact that all families have potable water available in the backyard, making it unnecessary to maintain a well in the field (Maputo City Municipal Council, 2016).

\section{Conclusion}

This article aimed to analyze the impact of urban requalification on municipal governance taking as its object of analysis the Chamanculo " $\mathrm{D}$ " neighborhood in Maputo municipality in Mozambique. Its execution resulted in a set of studies and projects necessary for the integrated requalification and regularization of the area, as well as actions to foster the socioeconomic development of the population residing in the area to carry out priority works. The requalification brought benefits to the city because it allowed the attribution of the Right of Use and Harnessing of Land (DUAT's) to the residents.

There was a greater flow of transport by residents within the area. Institutional negotiation was possible with Electricity of Mozambique (EDM) and Waters of the Maputo Region (ADEM) for the establishment of home connections that qualitatively improved the lives of the residents of the Chamanculo "D" neighborhood.

Residents of the neighborhood were involved in the requalification process. The requalification of the neighborhood has improved the collection of municipal solid waste, reduced the crime rate, created jobs, although small in scale, improved the circulation of people and goods, attracted more investment, slightly improved the collection of taxes and fees, (re) created urban quality of life and improved the quality of life of families. 
In principle they appear to be contradictory responses, i.e. most residents agree that requalification has brought about an improvement in quality of life, so it would be expected that requalification would satisfy everyone. During the interviews, some dissatisfaction of the residents was evident because the requalification brought separation between the families. Some families that traditionally lived broadly in a single nucleus with urban requalification had to be separated.

The ancestor worship made using some trees of symbolic value has sometimes been interrupted because the same trees with the requalification were destroyed, among other cases with a more concrete research on the preservation of cultural heritage in requalification would bring more accurate data.

Regarding the objectives initially intended and in accordance with the results obtained in this research, we found that they were achieved. Regarding the initial research question, what is the impact of urban requalification on municipal governance in the neighborhood of Chamanculo " $D$ ", it can be concluded that the urban requalification of this neighborhood was one of the means by Maputo municipality has used its governance process to inculcate local development. Therefore, this article concludes that the residents of Chamanculo " $D$ " neighborhood are generally satisfied with the requalification of their neighborhood.

\section{References}

Barquero, A. V (2001). Endogenous Development in Globalization Times. Porto Alegre: FEE.

Bastos, S. Q. A (2005). Space-Time Dysrhythmia: analysis of development strategies adopted in Juiz de Fora $(M G)$, post 70 years. Minas Gerais: Anais.

Benko, G. \& Pecqueur, B (2001). Territory resources and resource territories. Florianópolis: Geosul.

Borba, B (2000). The cognitive city. Sao Paulo: FAU / USP.

Buarque, S. C (1999). Sustainable Local and Municipal Planning and Development Methodology: Material for technical guidance and training of multipliers and technicians in local and municipal planning. Brasilia: MEPF / INCRA / IICA.

Carvalho, P. (2008). Cities and Landscape Appreciation of Water Fronts. In Biblos Journal of the Faculty of Letters of the University of Coimbra), Coimbra, Faculty of Letters, Volume VI (second series), pp. 328-329; 331-327; 337.

Domingues, A. (2006). City and Democracy - 30 years of Urban Transformation in Portugal. Argumentum, pp. 13; 22-24.

Enriquez, M. (1998). Fundamentals of Economics. São Paulo: Saraiva.

Ismail, M. (2019). The Problem of Property Rights to Land Acquisition of State (Jurisprudence and Conditions in Land National Law). Budapest International Research and Critics Institute-Journal (BIRCI-Journal), Volume 2, No 3, August 2019, pp. 68-77,

Juarez, P (2008). Local development: how to do it? Brasilia: SEBRAE.

Koehnen, T. \& Christopher, A (2006). Building a Social Development Network within a Rural Municipal Government in Portugal. Lisbon: Agricultural Economics Review.

Maputo City Municipal Council (2008). Five-Year Program of Maputo City Council, Maputo.

Maputo City Municipal Council (2009). Plan of urban structure of Maputo City Municipality, Maputo.

Maputo City Municipal Council (2016). Project "Support for the Rehabilitation of Chamanculo "C" Neighborhood. Report on the resettlement process of families covered by the works of Av. Amaral Matos and drainage ditch and actions to complete resettlement. Maputo.

Martins, G. I. V (2001). Local Development: from theory to practice. Campo Grande: UCDB.

National Institute Of Statistics (NIE) (2017). Statistical Yearbook. Maputo.

Niederle, P. A. \& Radomsky, G. F. W (2016). Introduction to development theories. Porto Alegre: UFRGS. 
Silva, A.M. R (2011). Urban requalification - The example of Polis intervention in Leiria. Master Dissertation in Geography, specialty in Spatial Planning and Development. College of Letters. Coimbra University.

Vaz, L. F.\& Silverira, C. B (1999). Central areas, urban projects and urban voids. Rio de Janeiro: Territory Magazine.

Yusnadi, Lubis, L. \& Nuraflah, C. A. (2019). Model of Communication Policy on the Development of the City without Slum (KOTAKU) Medan City. Budapest International Research and Critics Institute-Journal (BIRCI-Journal) Volume 2, No 2, May 2019, Page 284-292. 